\title{
Subcellular Segregation of Phosphoribulokinase and Ribulose-1,5- Bisphosphate Carboxylase/Oxygenase in the Cyanobacterium Chlorogloeopsis fritschii
}

\author{
By W. J. N. MARSDEN, T. LANARAS AND G. A. CODD* \\ Department of Biological Sciences, University of Dundee, Dundee DDI $4 H N, U K$
}

(Received 12 March 1984)

\begin{abstract}
The Calvin cycle enzyme phosphoribulokinase has been localized in terms of catalytic activity and enzyme protein in the cyanobacterium Chlorogloeopsis fritschii. In contrast to the $\mathrm{CO}_{2}$-fixing enzyme of the Calvin cycle, D-ribulose-1,5-bisphosphate carboxylase/oxygenase (RuBisCO), which occurs in the cytoplasm and in the carboxysomes, phosphoribulokinase is essentially $(95 \%)$ cytoplasmic in extracts from cells grown photoautotrophically to late exponential phase. Total phosphoribulokinase accounted for $0.6 \%$ of total cell protein in these cells. Immunochemical identity was found between the phosphoribulokinase located in the cytoplasm and the remaining enzyme $(5 \%)$ associated with the particulate fraction of the cell obtained following differential centrifugation. On density gradient centrifugation of the particulate fraction into Percoll plus sucrose the $\mathrm{RuBisCO}$ activity was located in a carboxysome band in the lower half of the gradient while the phosphoribulokinase activity essentially remained concentrated at the top of the gradient. Comparison of RuBisCO and phosphoribulokinase distributions suggests that the latter is not a carboxysomal enzyme in late exponential phase cells of $C$. fritschii.
\end{abstract}

\section{INTRODUCTION}

The polyhedral bodies of colourless sulphur-oxidizing bacteria, nitrite- and ammoniaoxidizing bacteria and cyanobacteria, all Calvin cycle autotrophs, have been found to contain the $\mathrm{CO}_{2}$-fixing enzyme of the Calvin cycle, D-ribulose-1,5-bisphosphate carboxylase/oxygenase (RuBisCO) (see Shively et al., 1973, 1977; Harms et al., 1981; Codd \& Stewart, 1976; Lanaras \& Codd, 1981 a). SDS-dissociation of isolated carboxysomes, followed by SDS-polyacrylamide gel electrophoresis has revealed several polypeptides, the most abundant being the large (L) and small (S) subunits of RuBisCO, which together account for more than $50 \%$ of total carboxysome protein (Lanaras \& Codd, $1981 a$; Cannon \& Shively, 1983). In addition to the RuBisCO L and S subunits, between 5 and about 11 other polypeptides can be seen in stained gels after electrophoresis (Biedermann \& Westphal, 1979; Lanaras \& Codd, $1981 a$; Cannon \& Shively, 1983). With the exception of two polypeptides with molecular weights of 10000 and 15000 , which may be Thiobacillus neapolitanus carboxysome shell components (Cannon \& Shively, 1983), no identities have been ascribed to the remaining carboxysomal polypeptides.

The possibility that $T$. neapolitanus carboxysomes may contain the remaining enzymes of the Calvin cycle, plus malate dehydrogenase, aspartate aminotransferase and adenylate kinase, has been raised (Beudeker \& Kuenen, 1981). Such an enzyme complement could enable carboxysomes to function as $\mathrm{CO}_{2}$-fixing organelles in which the reducing power and ATP needed to drive the Calvin cycle would be generated via an exogenous malate/aspartate shuttle system. Subsequent studies on isolated $T$. neapolitanus carboxysomes have not found ribose-5-phosphate

\footnotetext{
Abbreviations: RuBisCO, D-ribulose-1,5-bisphosphate carboxylase/oxygenase; RuBP, D-ribulose 1,5-bisphosphate; Ru5P, D-ribulose 5-phosphate.
} 
isomerase, fructose-1,6-bisphosphatase or phosphoribulokinase activities and the suggestion that the organelles may contain a fully functional Calvin cycle has been refuted (Cannon \& Shively, 1983).

We have isolated carboxysomes from the cyanobacterium Chlorogloeopsis fritschii and found a $39000 \mathrm{Dal}$ polypeptide among the dissociation products (Lanaras \& Codd, 1981a). Since phosphoribulokinase from this organism consists of subunits of molecular weight 40000 (Marsden \& Codd, 1984), we have determined whether the enzyme is carboxysomal in this organism. Subcellular localization studies based on enzyme activities have been complemented by quantitative immunoelectrophoresis using antiserum raised to the purified $C$. fritschii phosphoribulokinase.

\section{METHODS}

Organism and growth. Chlorogloeopsis fritschii 1411/16 from the Culture Centre of Algae and Protozoa, Cambridge, UK, was grown photoautotrophically in pure batch culture in BG-11 medium including nitrate (Stanier et al., 1971) as detailed previously (Codd \& Stewart, 1973).

Buffers. Buffer A contained $10 \mathrm{~mm}$-Tris/ $\mathrm{HCl}, 10 \mathrm{~mm}$-EDTA (disodium salt), $50 \mathrm{~mm}-\mathrm{NaHCO}_{3}$ and $80 \mathrm{~mm}-2-$ mercaptoethanol, $\mathrm{pH} 8.0$ at $4^{\circ} \mathrm{C}$. Buffer B contained $100 \mathrm{~mm}$-Tris/HCl, $10 \mathrm{~mm}$-EDTA (disodium salt), $50 \mathrm{~mm}$ $\mathrm{NaHCO}_{3}$ and $80 \mathrm{~mm}$-mercaptoethanol, $\mathrm{pH} 8.0$ at $4^{\circ} \mathrm{C}$.

Preparation of cell-free extracts. Mid to late exponential phase cells were used throughout and all steps were performed at $4^{\circ} \mathrm{C}$ unless stated otherwise. Cells were obtained by centrifuging 181 culture at $2000 \mathrm{~g}$ for $10 \mathrm{~min}$. Then 3-5 $\mathrm{g}$ wet wt of cells were washed, resuspended in about 5 vols buffer $\mathrm{A}$, and broken by passage through an ice-cold French press at $110 \mathrm{mPa}$. Unbroken cells and large fragments were removed by centrifugation at $1500 \mathrm{~g}$ for $10 \mathrm{~min}$ and the supernatant was used for differential centrifugation.

Differential centrifugation. The $1500 \mathrm{~g}$ cell-free supernatant was centrifuged at $40000 \mathrm{~g}$ for $1 \mathrm{~h}$. The pellet was resuspended in 3 vols buffer $B$ and ultrasonicated for $4 \times 30$ s with 30 s intermittent cooling in an MSE Soniprep $150(9.5 \mathrm{~mm}$ probe). The volumes of the supernatant and resuspended ultrasonicated pellet fractions were recorded to permit estimation of enzyme distribution and they were retained for enzyme activity and immunology assays.

Density gradient centrifugation. The $40000 \mathrm{~g}$ pellet was resuspended in buffer $A$ and $1.7 \mathrm{ml}$ vols were loaded onto $20 \mathrm{ml}$ density gradients of Percoll plus sucrose in buffer A, prepared as before (Lanaras \& Codd, 1981 a). The gradients were spun in a $3 \times 25 \mathrm{ml}$ swing-out rotor at $27000 \mathrm{~g}$ in an MSE Prepspin 75 centrifuge for $2.5 \mathrm{~h}$. Fractions of $1 \mathrm{ml}$ were collected from the bottom of the gradients by suction. Density was determined as before (Lanaras \& Codd, 1981a) and fractions were retained for assays of total protein, chlorophyll, RuBisCO and phosphoribulokinase.

Enzyme assays. RuBisCO (EC 4.1.1.39) carboxylase activity was measured by preincubation of samples for 10 min in a final volume of $0.1 \mathrm{ml}$ containing $100 \mathrm{~mm}$-Bicine, $\mathrm{pH} 7.8$ at $30^{\circ} \mathrm{C}, 10 \mathrm{mM}-\mathrm{MgCl}_{2}, 50 \mathrm{mM}-\mathrm{NaH}^{14} \mathrm{CO}_{3}$ $\left(74 \mathrm{kBq} \mu \mathrm{mol}^{-1}\right), 1 \mathrm{~mm}$-EDTA (disodium salt) and $1 \mathrm{mM}$-DTT. Catalysis was initiated by the addition of $50 \mu \mathrm{l}$ RuBP to a final concentration of $0.5 \mathrm{~mm}$ and was allowed to run for $2 \mathrm{~min}$ at $30^{\circ} \mathrm{C}$ before termination by the addition of $50 \mu \mathrm{l} 50 \%(\mathrm{w} / \mathrm{v}) \mathrm{TCA}$. Vials were heated to $100^{\circ} \mathrm{C}$ in a water bath for $1 \mathrm{~h}$ and the acid-stable radioactivity that was incorporated was measured by standard liquid scintillation counting. Specific radioactivity of the $\mathrm{NaH}^{14} \mathrm{CO}_{3}$ was determined; controls lacked RuBP.

Phosphoribulokinase (EC 2.7.1.19) activity was measured by coupling Ru5P-plus ATP-dependent RuBP formation to the $\mathrm{RuBisCO}$ assay run in the presence of excess exogenous spinach $\mathrm{RuBisCO}$, as detailed earlier (Marsden \& Codd, 1984).

Phosphoribulokinase purification and antiserum production. The $C$. fritschii phosphoribulokinase was purified according to Marsden \& Codd (1984). A $0.5 \mathrm{ml}$ sample of electrophoretically homogeneous enzyme containing $320 \mu \mathrm{g}$ protein was emulsified with an equal volume of Complete Freund's Adjuvant and injected subcutaneously into a New Zealand White rabbit. Null serum was collected by bleeding prior to injection. Three booster injections of 200,120 and $120 \mu \mathrm{g}$ phosphoribulokinase protein in $0.5 \mathrm{ml}$ were emulsified with equal volumes of Incomplete Freund's Adjuvant and injected subcutaneously at $14 \mathrm{~d}$ intervals. Blood was taken $14 \mathrm{~d}$ after the last injection. Null serum and antiserum were prepared by allowing blood to clot overnight at $4{ }^{\circ} \mathrm{C}$ followed by centrifugation at $2000 \mathrm{~g}$ for $10 \mathrm{~min}$. The serum was concentrated threefold by precipitation with $50 \%$ saturation $\left(\mathrm{NH}_{4}\right)_{2} \mathrm{SO}_{4}$. The precipitated material was recovered by spinning at $40000 \mathrm{~g}$ for $30 \mathrm{~min}$ and resuspended in $10 \mathrm{~mm}$-phosphate buffer, pH 7.5 at $4^{\circ} \mathrm{C}$, containing $0.15 \mathrm{M}-\mathrm{NaCl}$, and dialysed overnight against the same buffer. The sera were dispensed into $100 \mu \mathrm{l}$ volumes and stored at $-20^{\circ} \mathrm{C}$.

Immunological methods. Ouchterlony double immunodiffusion using $C$. fritschii phosphoribulokinase antiserum was carried out on $5 \times 5 \mathrm{~cm}$ glass plates supporting $4.4 \mathrm{ml}$ Indubiose Agarose A37 in 0.1 M-potassium phosphate buffer, $\mathrm{pH} 7.5$, containing $0.005 \mathrm{~g}$ sodium azide $\mathrm{l}^{-1}$. Wells of $10 \mu \mathrm{l}$ were loaded with sera and enzyme preparations 
and incubated overnight at $4{ }^{\circ} \mathrm{C}$. The gels were fixed in $0 \cdot 1 \mathrm{M}-\mathrm{NaCl}$ for $30 \mathrm{~min}$ and washed in distilled water for $30 \mathrm{~min}$ prior to pressing and drying. Gels were stained with Coomassie Blue G250 $\left(5 \mathrm{~g}^{-1}\right)$ in $45 \%(\mathrm{v} / \mathrm{v})$ methanol, $10 \%(\mathrm{v} / \mathrm{v})$ acetic acid in water. Destaining was done in the same mixture minus Coomassie Blue.

Rocket immunoelectrophoresis was carried out using $C$. fritschii phosphoribulokinase antiserum and $\mathrm{RuBisCO}$ antiserum against the enzyme from the cyanobacterium Microcystis PCC 7820 (provided by S. Murray of this laboratory). Experimental details were as given by Lanaras \& Codd (1981b).

Protein determination. Protein concentrations were measured according to Bradford (1976) with $10 \mu \mathrm{l}$ samples, $1 \mathrm{ml}$ reagent and crystalline BSA as a standard.

Chemicals. $\mathrm{NaH}^{14} \mathrm{CO}_{3}$ was obtained from Amersham. Agarose $\mathrm{C}$ was from Pharmacia and DTT, BSA, Ru5P, RuBP and spinach RuBisCO from Sigma. ATP was from Boehringer and Coomassie Brilliant Blue G250 was from Serva, Heidelberg, FRG. Indubiose A37 was from L'Industrie Biologique Française, Genevilliers, France. All other chemicals were from BDH and were used at the highest purity commercially available.

\section{RESULTS AND DISCUSSION}

Cell-free extracts were prepared from Chlorogloeopsis fritschii under conditions which favour carboxysome isolation and the separation of soluble (cytoplasmic) and particulate (carboxysomal) RuBisCO (Lanaras \& Codd, 1981a). The distribution of RuBisCO and phosphoribulokinase activities and the enzyme protein content in $40000 \mathrm{~g}$ supernatant and particulate (carboxysome-containing) extracts is shown in Table 1 . About $40 \%$ of the extractable RuBisCO activity was particulate, whereas only $5 \%$ of the total phosphoribulokinase activity was sedimented. Exhaustive dialysis against fresh buffer B did not influence either enzyme activity, precluding reversible inhibition by low molecular weight metabolites in the fractions.

Since rates of $\mathrm{RuBisCO}$ activity per unit $\mathrm{RuBisCO}$ protein can vary widely in such preparations (Lanaras \& Codd, 1982), levels of enzyme protein were also measured using antisera to RuBisCO purified from Microcystis PCC 7820 and to phosphoribulokinase from C. fritschii. As before, the RuBisCO antiserum cross-reacted to form single immunoprecipitation bands versus C. fritschii extracts in Ouchterlony gels and formed rockets in immunoelectrophoresis gels to enable quantification of RuBisCO protein (Lanaras \& Codd, 1981 b). Phosphoribulokinase antiserum has not been produced previously against the cyanobacterial enzyme; the behaviour of the antiserum against the homologous pure antigen and against the $40000 \mathrm{~g}$ supernatant and particulate extracts of $C$. fritschii is shown in Fig. $1(a)$. Single immunoprecipitation bands were formed in all cases. Immunochemical identity between the soluble and particulate phosphoribulokinase preparations was indicated by the complete fusion between respective bands.

A linear relationship was established between rocket height and antigen concentration which enabled the enzyme protein to be quantified in the cell-free extracts (Fig. $1 b$ ). The levels of $\mathrm{RuBisCO}$ and phosphoribulokinase protein were thereby measured and are compared in Table 1. Over $20 \%$ of total RuBisCO protein was particulate (carboxysomal) in the differential centrifugation fractions, whereas less than $2 \%$ of phosphoribulokinase protein was sedimented. Comparison of the relative levels of the enzymes within each fraction reveals considerable

\section{Table 1. Distribution of RuBisCO and phosphoribulokinase activities and proteins in soluble and} particulate fractions of Chlorogloeopsis fritschii

\begin{tabular}{clccccc}
\multicolumn{1}{c}{ Enzyme } & Fraction* & $\begin{array}{c}\text { Specific } \\
\text { activity† }\end{array}$ & $\begin{array}{c}\text { Distribution } \\
\text { of activity } \\
(\%) \ddagger\end{array}$ & $\begin{array}{c}\text { Enzyme } \\
\text { protein } \\
(\mathrm{mg})\end{array}$ & $\begin{array}{c}\text { Distribution } \\
\text { of enzyme } \\
\text { protein } \\
(\%)\end{array}$ & $\begin{array}{c}\text { Distribution of enzyme } \\
\text { protein as a } \\
\text { percentage of protein } \\
\text { in the fraction }\end{array}$ \\
RuBisCO & Supernatant & 0.867 & 62.20 & 5.14 & 78.50 & 12.80 \\
Phosphoribulokinase & Pellet & 0.383 & 38.80 & 0.47 & 21.50 & 23.41 \\
& $\begin{array}{l}\text { Supernatant } \\
\text { Pellet }\end{array}$ & 1.261 & 95.08 & 0.18 & 98.29 & 0.67 \\
& & 3.752 & 4.92 & 0.00313 & 1.71 & 0.08
\end{tabular}

- Supernatant and particulate fractions obtained after centrifugation of a $1500 \mathrm{~g}$ broken cell-free supernatant at $40000 \mathrm{~g}$ for $1 \mathrm{~h}$. Total soluble and particulate fractions contained 26.15 and $4.04 \mathrm{mg}$ protein, respectively.

$\dagger$ nmol substrate transformed $\min ^{-1}$ ( $\mu \mathrm{g}$ enzyme protein $)^{-1}$.

$\ddagger$ Percentage of activity originally present in a $1500 \mathrm{~g} \times 10 \mathrm{~min}$ supernatant after further separation into the $40000 \mathrm{~g} \times 1 \mathrm{~h}$ supernatants and pellets. 


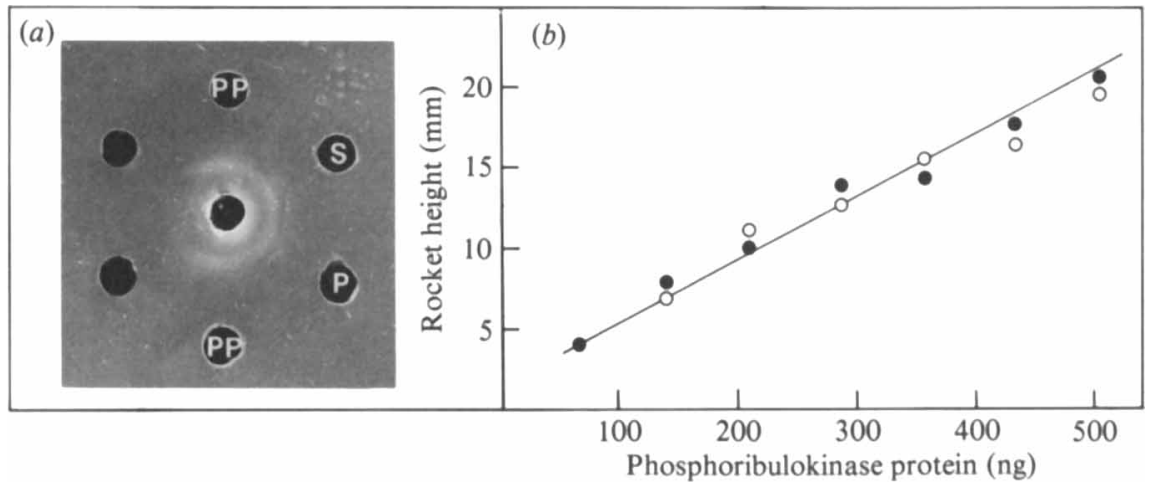

Fig. 1. Immunological detection and assay of phosphoribulokinase from Chlorogloeopsis fritschii. (a) Ouchterlony double immunodiffusion gel. Centre well, phosphoribulokinase antiserum. Peripheral wells were loaded as follows: PP, purified homologous phosphoribulokinase antigen; $\mathrm{S}, 40000 \mathrm{~g}$ supernatant $; \mathrm{P}, 40000 \mathrm{~g}$ resuspended ultrasonicated pellet of $C$. fritschii extract. (b) Typical rocket immunoelectrophoresis calibration gel of purified $C$. fritschii phosphoribulokinase versus homologous antiserum. Wells were loaded with 1 to $7 \mu \mathrm{l}$ purified enzyme containing up to $540 \mathrm{ng}$ protein. The $3.3 \mathrm{ml}$ Agarose $\mathrm{C}$ gels contained $75 \mu \mathrm{l}$ antiserum and were electrophoresed at $4 \mathrm{~mA}$ for $18 \mathrm{~h}(\mathrm{O}$, , duplicate calibrations).

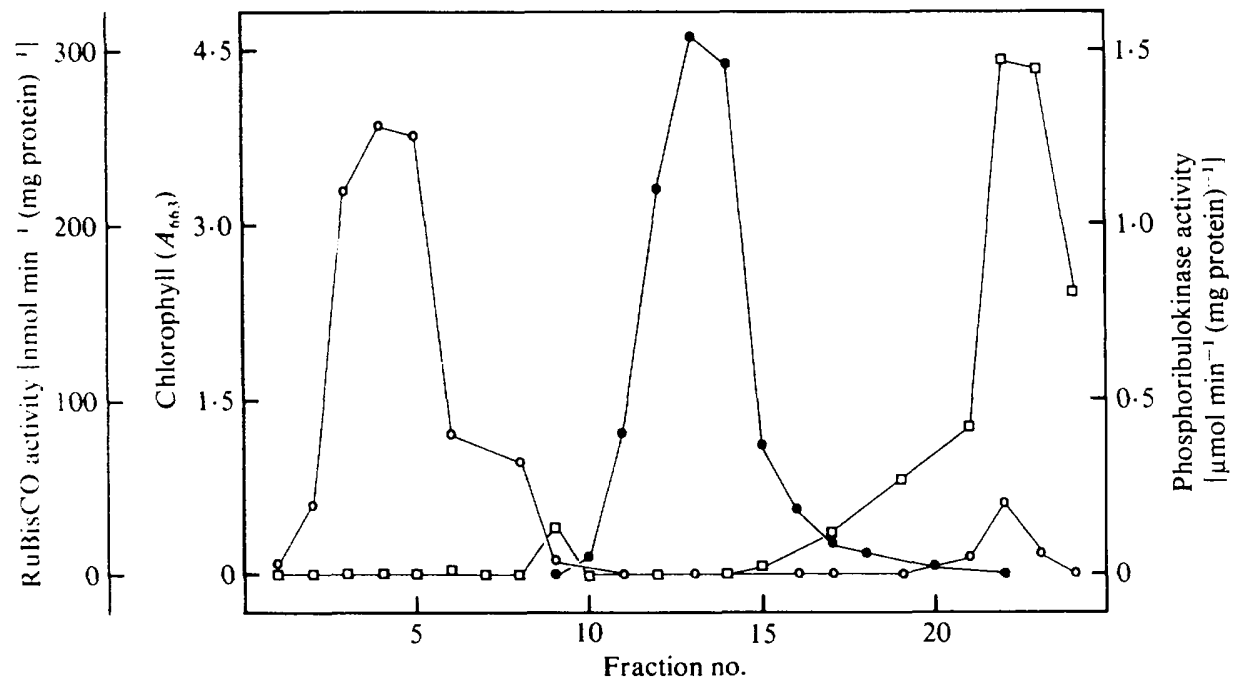

Fig. 2. Distribution of Chlorogloeopsis fritschii RuBisCO (carboxylase) and phosphoribulokinase activities after centrifugation of $40000 \mathrm{~g}$ pellet material into Percoll plus sucrose density gradients (for details see Lanaras \& Codd, $1981 \mathrm{a}$ ). Fractions of $1 \mathrm{ml}$ were collected from the bottom of the gradients. $\bigcirc$, RuBisCO carboxylase activity; , chlorophyll $\left(A_{663}\right) ; \square$, phosphoribulokinase activity. Fractions are numbered in the order in which they were withdrawn from the gradient, fraction 1 being from the bottom.

disparity : the ratio of $\mathrm{RuBisCO}$ to phosphoribulokinase is $28: 1$ in the soluble fraction and $150: 1$ in the particulate fraction (calculated from Table 1). On a total protein basis, phosphoribulokinase was about 10 times more abundant in the soluble fraction than in the particulate, while $\mathrm{RuBisCO}$ was twice as abundant in the soluble fraction compared to the particulate fraction. Total RuBisCO protein accounted for $18.2 \%$ of the total cellular $C$. fritschii protein, a level which is similar to total RuBisCO levels in other autotrophic prokaryotes (Beudeker et al., 1981; Leadbeater et al., 1982). Total phosphoribulokinase protein amounted to $0.6 \%$ of the total protein in these extracts of photoautotrophically-grown $C$. fritschii, which compares with values determined in chemolithoautotrophic cultures of Alcaligenes eutrophus (Leadbeater et al., 1982).

Further localization studies were made to determine whether the small amount of particulate 
C. fritschii phosphoribulokinase was associated with carboxysomes. Profiles of RuBisCO and phosphoribulokinase activities are shown in Fig. 2, after centrifugation of the resuspended $40000 \mathrm{~g}$ pellet material into density gradients of Percoll plus sucrose. As before (Lanaras \& Codd, $1981 a$ ), the RuBisCO activity was focussed in a carboxysome band in the lower half of the gradient below the chlorophyll-containing thylakoid band. The phosphoribulokinase activity originally associated with the $40000 \mathrm{~g}$ pellet fraction essentially remained concentrated at the top of the gradients (Fig. 2). It is thus possible that the particulate phosphoribulokinase represents soluble enzyme molecules which may be adsorbed onto cell fragments during cell disruption.

In conclusion, the possibility that phosphoribulokinase is associated with carboxysomes in $C$. fritschii is not favoured since enzyme activity and protein distributions do not mimic those of $\mathrm{RuBisCO}$. The data show no enrichment of crude particulate fractions or isolated $C$. fritschii carboxysomes with phosphoribulokinase. Indeed the distribution of this enzyme in the cyanobacterial extracts closely resembles that found in similarly prepared fractions from the purple non-sulphur bacterium Rhodopseudomonas palustris 1850, which does not appear to contain polyhedral bodies $(96 \%$ soluble, $4 \%$ particulate phosphoribulokinase; W. J. N. Marsden, unpublished observations). The possibilities that other Calvin cycle enzymes, in addition to RuBisCO, may be present in cyanobacterial carboxysomes, and that the inclusion bodies may be active sites of $\mathrm{CO}_{2}$ fixation, are not discounted. However, the absence of phosphoribulokinase alone, due to its specific and essential role in the regeneration of the $\mathrm{CO}_{2}$ acceptor $\mathrm{RuBP}$, would preclude a fully functional Calvin cycle in $C$. fritschii carboxysomes.

We gratefully acknowledge financial support from the Nuffield Foundation and thank K. A. Beattie for able technical assistance.

\section{REFERENCES}

BrADFORD, M. M. (1976). A rapid and sensitive method for the quantitation of microgram quantities of protein utilising the principle of protein dye binding. Analytical Biochemistry 72, 248-254.

Beudeker, R. F. \& Kuenen, J. G. (1981). Carboxysomes: 'Calvinosomes'? FEBS Letters 131, 269-274.

Beudeker, R. F., Codd, G. A. \& Kuenen, J. G. (1981). Quantification and intracellular distribution of ribulose 1,5-bisphosphate carboxylase in Thiobacillus neapolitanus, as related to possible functions of carboxysomes. Archives of Microbiology 129, 361367.

Biedermann, M. \& Westphal, K. (1979). Chemical composition of $\mathrm{NB}_{1}$ particles from Nitrobacter agilis. Archives of Microbiology 121, 187-191.

Cannon, G. C. \& Shively, J. M. (1983). Characterization of a homogeneous preparation of carboxysomes from Thiobacillus neapolitanus. Archives of Microbiology 134, 52-59.

CODD, G. A. \& SteWART, W. D. P. (1973). Pathways of glycollate metabolism in the blue-green alga Anabaena cylindrica. Archiv für Mikrobiologie 94, 11-28.

Codd, G. A. \& Stewart, W. D. P. (1976). Polyhedral bodies and ribulose 1,5-diphosphate carboxylase of the blue-green alga Anabaena cylindrica. Planta 130, 323-326.

Harms, H., KoOPS, H.-P., Martiny, H. \& WullenWEBER, M. (1981). D-Ribulose 1,5-bisphosphate carboxylase and polyhedral inclusion bodies in Nitrosomonas spec. Archives of Microbiology 128, 280-281.

Lanaras, T. \& Codd, G. A. (1981a). Ribulose 1,5bisphosphate carboxylase and polyhedral bodies of
Chlorogloeopsis fritschii. Planta 153, 279-285.

Lanaras, T. \& CODD, G. A. (1981b). Structural and immunoelectrophoretic comparison of soluble and particulate ribulose bisphosphate carboxylases from the cyanobacterium Chlorogloeopsis fritschii. Archives of Microbiology 130, 213-217.

Lanaras, T. \& CODD, G. A. (1982). Variations in ribulose 1,5-bisphosphate carboxylase protein levels, activities and subcellular distribution during photoautotrophic batch culture of Chlorogloeopsis fritschii. Planta 154, 284-288.

Leadbeater, L., Siebert, K., Schobert, P. \& Bowien, B. (1982). Relationship between activities and protein levels of ribulose-bisphosphate carboxylase and phosphoribulokinase in Alcaligenes eutrophus. FEMS Microbiology Letters 14, 263-266.

Marsden, W. J. N. \& Codd, G. A. (1984). Purification and molecular and catalytic properties of phosphoribulokinase from the cyanobacterium Chlorogloeopsis fritschii. Journal of General Microbiology 130, 9991006.

Shively, J. M., Ball, F. L., Brown, D. H. \& SAUNDERS, R. E. (1973). Functional organelles in prokaryotes: polyhedral bodies (carboxysomes) of Thiobacillus neapolitanus. Science 182, 584-586.

Shively, J. M., BocK, E., Westphal, K. \& Cannon, G. C. (1977). Icosahedral inclusions (carboxysomes) of Nitrobacter agilis. Journal of Bacteriology 132, 673675.

Stanier, R. Y., Kunisawa, R., MANdel, M. \& CohenBAZIRE, G. (1971). Purification and properties of unicellular blue-green algae (order Chroococcales). Bacteriological Reviews 35, 171-205. 